Supporting Information for:

\title{
Surface-Only Spectroscopy for Diffusion-Limited Systems Using Ultra-Low Temperature DNP MAS NMR at 16.4 T
}

\author{
Yoh Matsuki, ${ }^{\dagger \perp}$ Tomoaki Sugishita, ${ }^{\dagger}$ Toshimichi Fujiwara ${ }^{\dagger *}$ \\ †nstitute for Protein Research, Osaka University, Suita, Osaka 565-9871, Japan \\ ${ }^{\perp}$ Center for Quantum Information and Quantum Biology, Institute for Open and Transdisciplinary \\ Research Initiatives, Osaka University, Suita, Osaka 565-9871, Japan
}

Table S1 DNP enhancement factors previously reported for benchmarking small molecules (urea/proline), biological macromolecules and pharmaceutical small molecule crystals at $\sim 100 \mathrm{~K}$. The polarizing agent is AMUPol unless otherwise noted.

\begin{tabular}{|c|c|c|c|c|c|c|c|}
\hline Sample & $\varepsilon_{\text {on } / \text { off }}$ & $B_{0}(\mathrm{~T})$ & $\xi^{(1)}$ & $\varepsilon_{\text {on/off }} \xi$ & $\rho_{(\mathrm{CH} 3)}^{(2)}$ & $T(\mathrm{~K})$ & Ref. \\
\hline Urea & 150 & 14.1 & 0.74 & 111 & 0 & 108 & $\# \#^{[1]}$ \\
\hline Proline & 220 & 9.4 & 0.33 & 72 & 0 & 110 & $\#^{[2]}$ \\
\hline HHRz & 240 & 9.4 & 0.33 & 79 & 0 & 104 & $\#^{[3]}$ \\
\hline $\begin{array}{c}\text { Salicylic } \\
\text { Acid }\end{array}$ & 200 & 9.4 & 0.33 & 66 & 0 & 105 & $\#{ }^{[4]}$ \\
\hline T4SScc & 60 & 9.4 & 0.33 & 20 & 0.29 & 110 & $\# \#^{[5]}$ \\
\hline SH3 crystal & 31 & 9.4 & 0.33 & 10 & 0.60 & 100 & $\# \#^{[6]}$, totapol \\
\hline KcsA & 8.3 & 18.8 & 1.3 & 11 & 0.74 & 100 & $\# \#^{[7]}$ \\
\hline MLF & 1.2 & 16.4 & 1.0 & 1.2 & 1.0 & 100 & Our data \\
\hline Theophilline & 8 & 9.4 & 0.33 & 2.6 & 2.0 & 105 & $\#^{[4]}$, \\
\hline $\begin{array}{c}\text { Crystalline } \\
\text { GNNQQNY }\end{array}$ & 20 & 9.4 & 0.33 & 6.6 & 0 & 100 & $\#\left[{ }^{[8]}\right.$, totapol \\
\hline
\end{tabular}

(1) $\xi=\left(B_{0} / 16.4\right)^{2}$, a conversion factor to the enhancement at $16.4 \mathrm{~T}$; according to Mance et al. ${ }^{[9]}$

(2) Oftentimes, intrinsic $T_{1 \mathrm{H}}$ of the system is not reported, and thus the methyl-group density may serve as an indicator.

The hammer-head ribozyme (HHRz) and salicylic acid crystal samples with $\rho\left(\mathrm{CH}_{3}\right)=0$ 
showed exceptionally high enhancements similar to those for urea and proline, while typical protein samples with $\rho\left(\mathrm{CH}_{3}\right)=0.3-0.6$ exhibited generally lower enhancements. Enhancements were even lower for membrane proteins which tends to have $\rho\left(\mathrm{CH}_{3}\right)>0.7$. Microcrystalline Theophilline and MLF with $\rho\left(\mathrm{CH}_{3}\right)=2.0$ and 1.0, respectively, yielded very small enhancement at $100 \mathrm{~K}$. As such, there was no mention on the DNP enhancement for other methyl-bearing crystalline peptides such as Ala-Phe-Gly (APG) and N-acetyl Val-Leu (N-ac-VL) in their low-temperature MAS DNP study. ${ }^{[10]}$ A prominent outlier is the crystalline GNNQQNY, for which only a very small enhancement factor has been observed notwithstanding the absence of methyl group. The possible causes are discussed in the main text. 


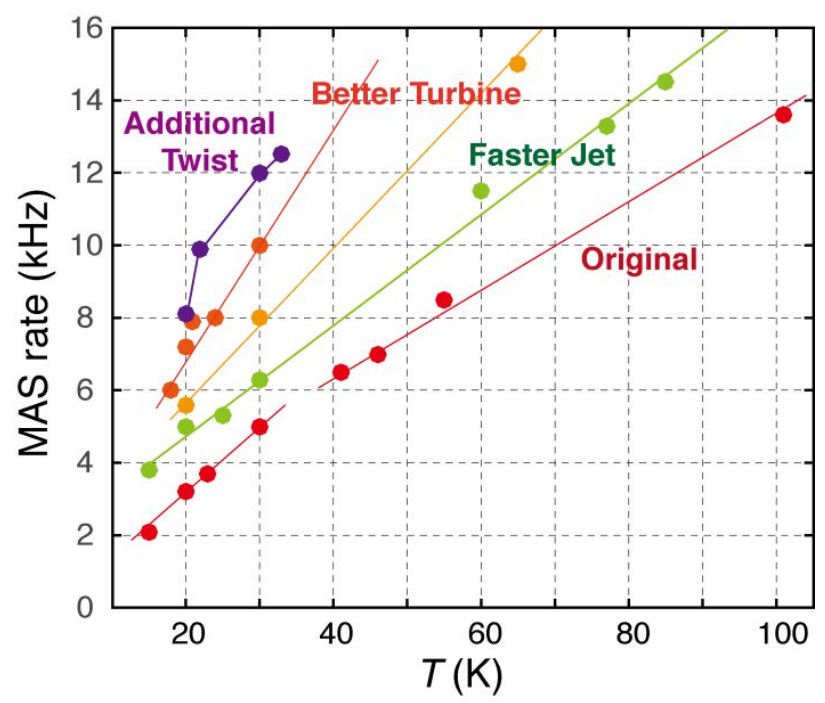

Fig. S1 Maximum MAS rate achieved in various phase of the development of the Closedcycle He MAS NMR probe system. All the MAS rate plotted is subject to a long-term (>days) stability $( \pm 5 \mathrm{~Hz})$. 


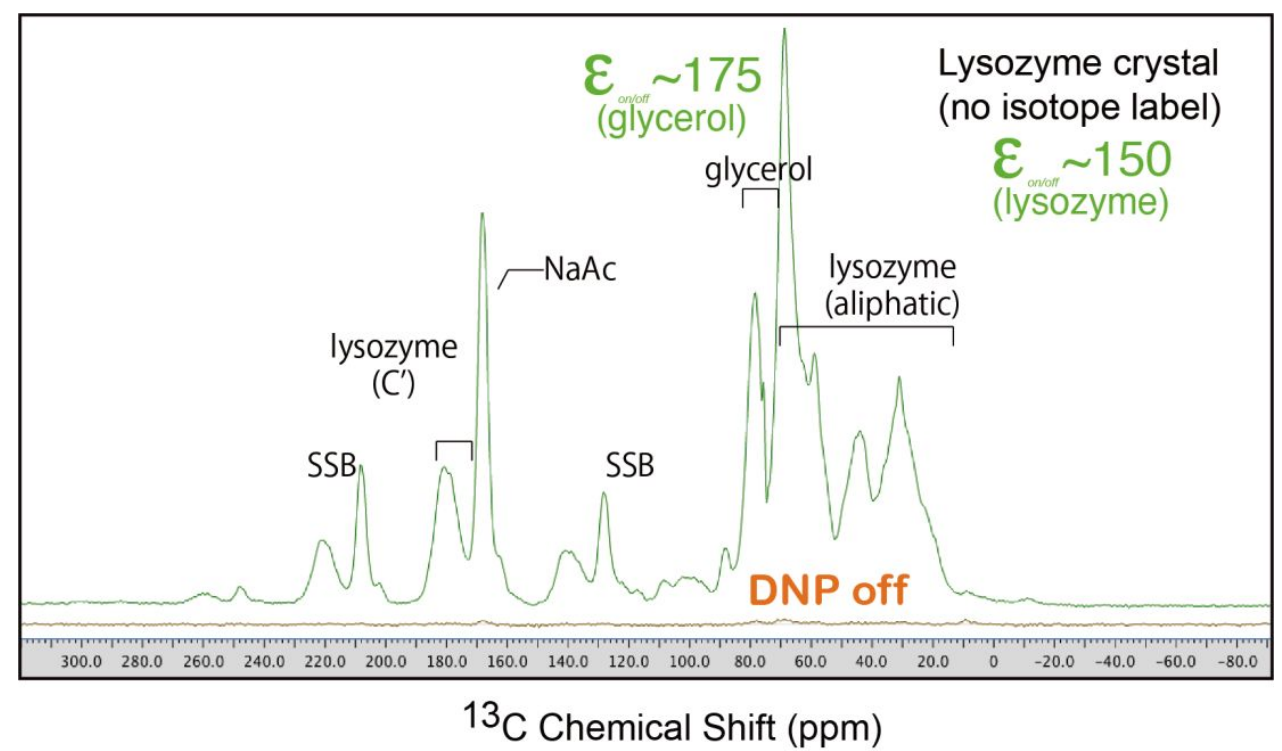

Fig. S2 ${ }^{13} \mathrm{C}$ CP spectra of fully-protonated microcrystalline lysozyme wet with $20 \mathrm{mM}$ AMUpol-doped glycerol matrix with MW on (green) and off (orange). The enhancement factor of $\varepsilon>150$ was obtained at $T=35 \mathrm{~K}, v_{\mathrm{R}}=8.8 \mathrm{kHz}, B_{0}=16.4 \mathrm{~T}$. The enhancement was slightly $(\sim 15 \%)$ larger for glycerol than for lysozyme signals. 

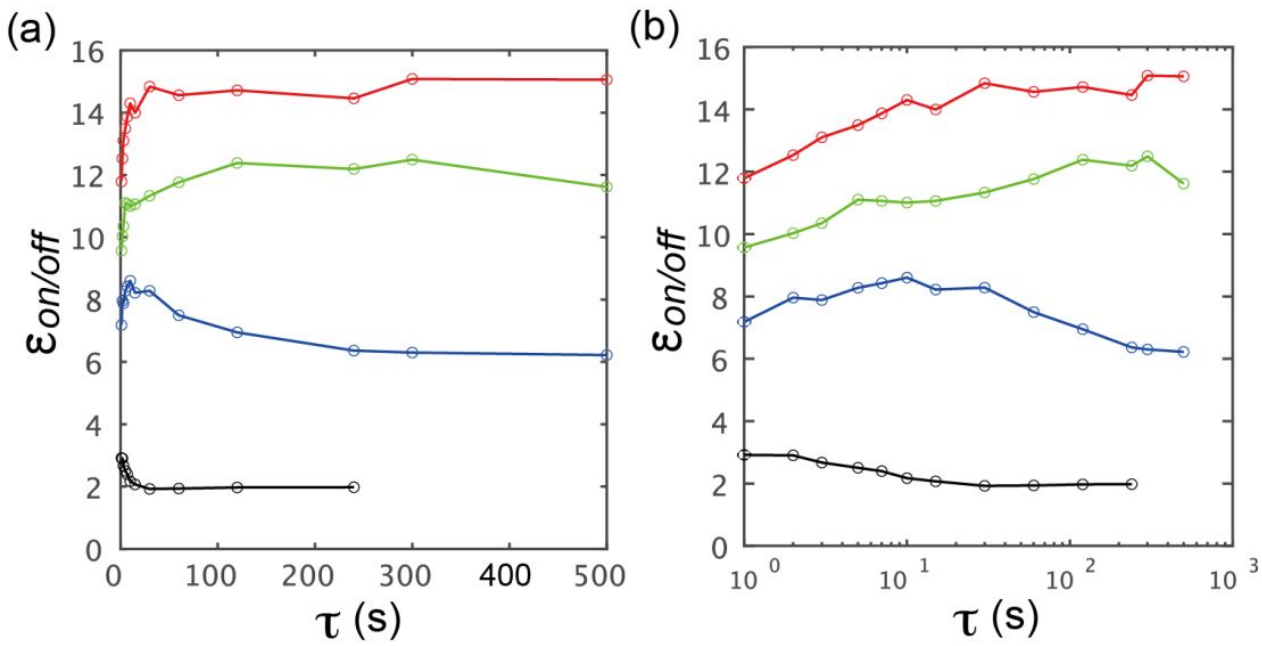

Fig. S3 Enhancement factor as a function of the polarization buildup delay $\tau$ measured at $86 \mathrm{~K}$ (black), $55 \mathrm{~K}$ (blue), $34 \mathrm{~K}$ (green) and $27 \mathrm{~K}$ (red) plotted in the linear (a) and in the log scale (b) for the delay. 

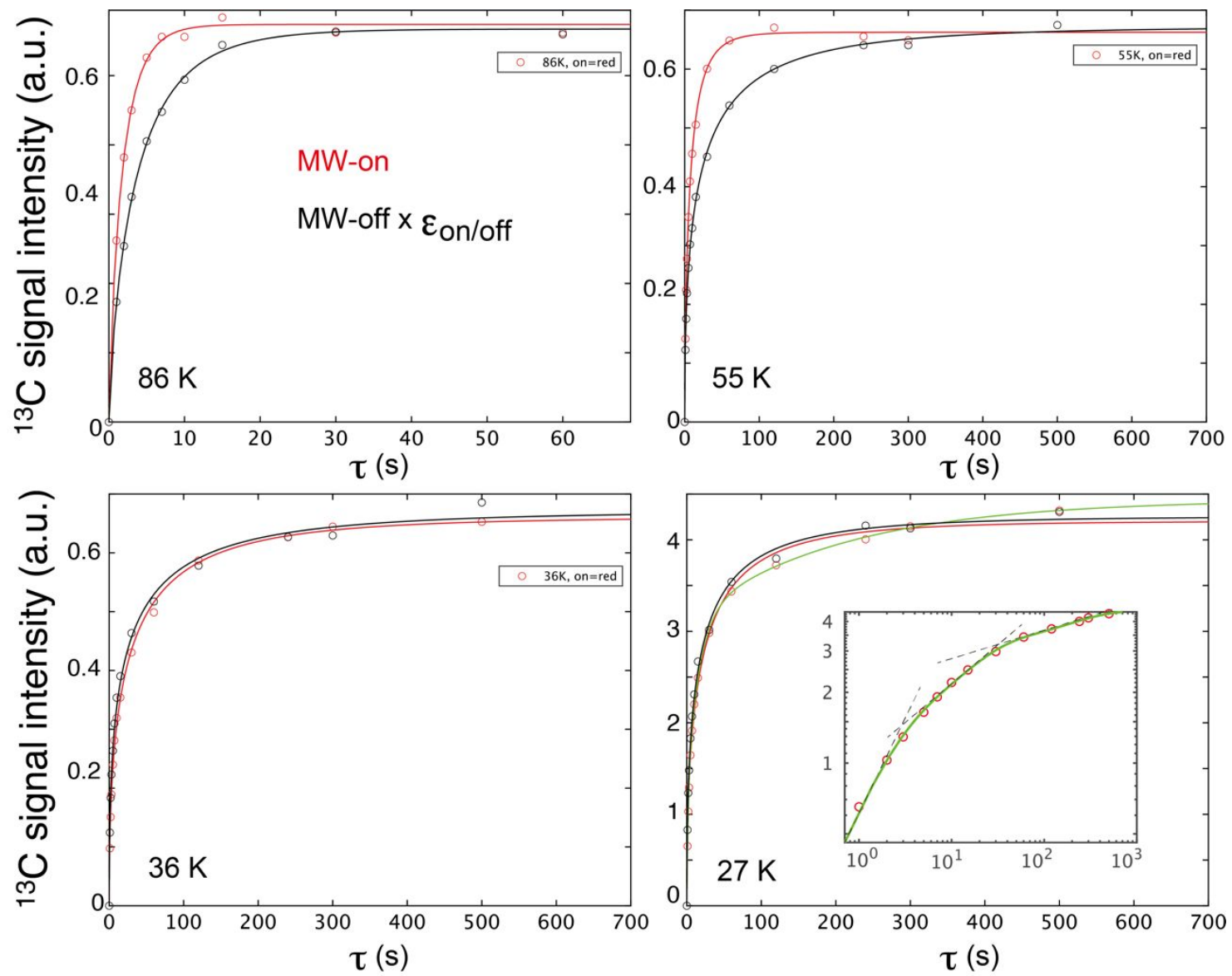

Fig. S4 Experimental (circles) and stretched-exponential fitting (red lines) of the polarization buildup curves recorded at indicated sample temperature. Faster buildups for the MW-on signal seen at 86 and $55 \mathrm{~K}$ have been explained by the fast polarization penetration due to large polarization gradient at the thin source-to-target boundary. ${ }^{[11]}$ The MW-on data at $27 \mathrm{~K}$ was also fitted with a triple exponential function (green line) with a normalized least-square residual of 0.0013 which is similar to that with the stretched exponential function, 0.0079 . The weights and time constants for the three components were: $[0.27,1.9 \mathrm{~s}],[0.43,16 \mathrm{~s}],[0.30,208 \mathrm{~s}]$, respectively. The inset shows the log-log plot for the triple-exponential fitting. 
(a)

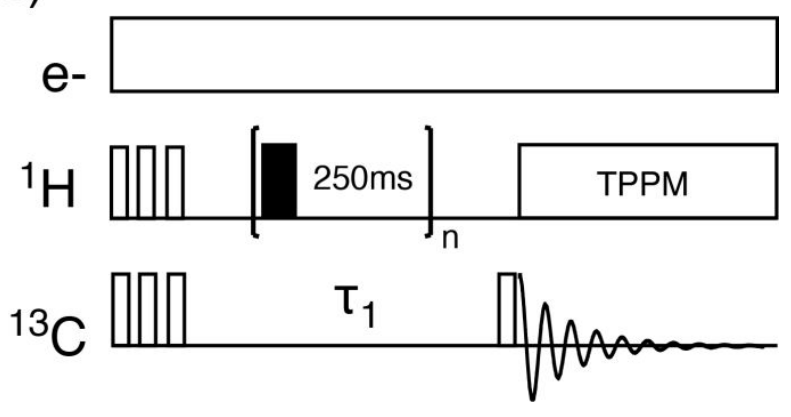

(b)

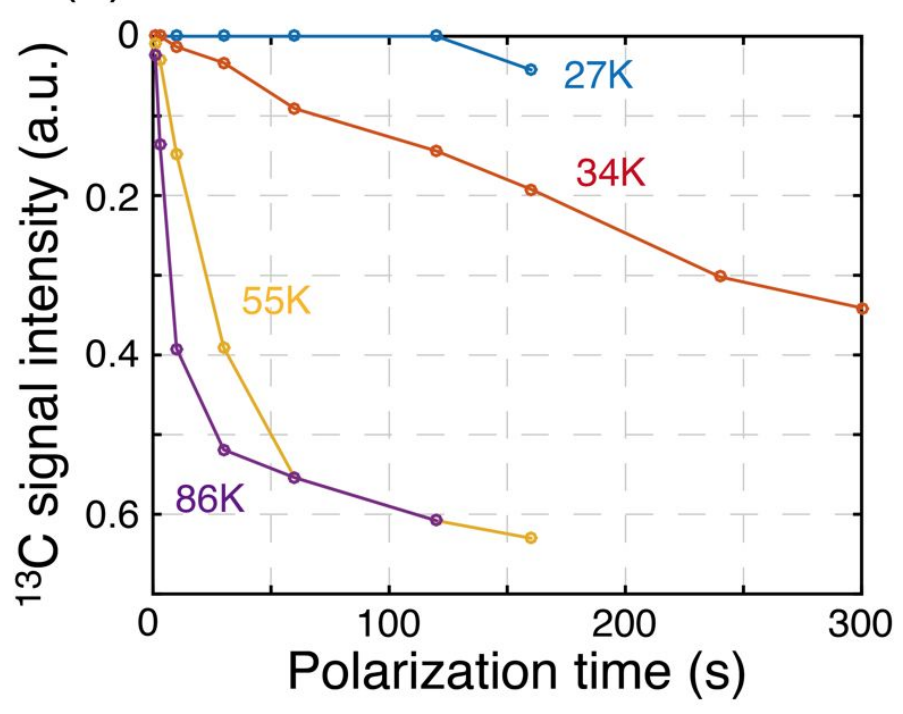

Fig. S5 (a) The gradual arrest of the methyl-group rotation at ULT is evidenced by progressively decreasing heteronuclear NOE. The pulse sequence used to record hetero-nuclear NOE effect. The data taken with and without ${ }^{1} \mathrm{H}$ saturation pulses during the buildup (filled black rectangle) were subtracted to each other to observe the pure NOE effect. (b) The heteronuclear NOE buildup curves recorded at indicated temperature. Significant reduction of heteronuclear NOE is seen below $\sim 60 \mathrm{~K}$ which culminated with almost no NOE at $27 \mathrm{~K}$. 

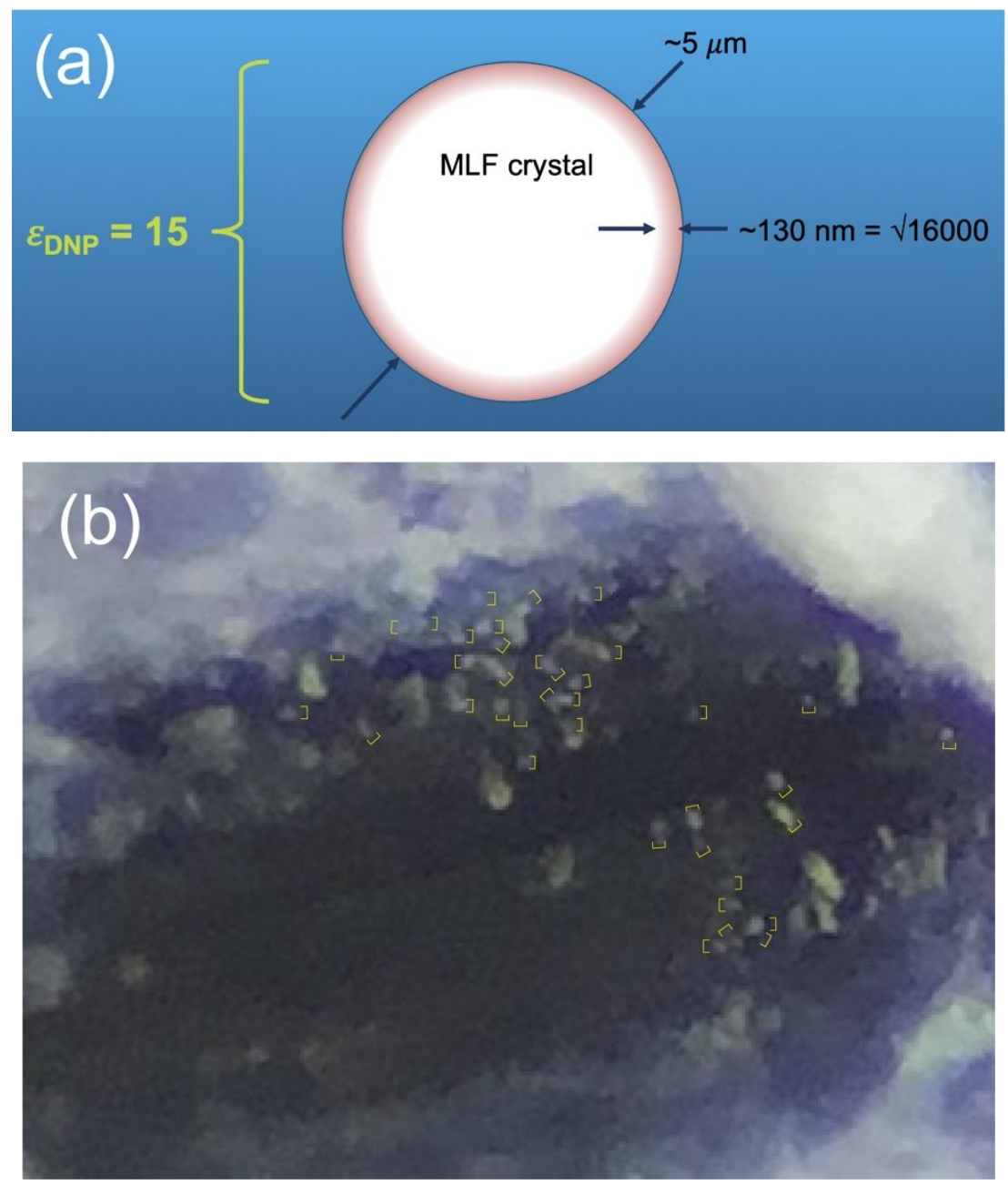

Fig. S6 (a) A surface-polarized spherical MLF crystallite model used for the estimation of the surface enhancement. Crystal core is assumed to be thermally polarized, i.e., $\epsilon_{\mathrm{on} / \mathrm{off}}^{\text {core }}=1$ is implied in the equation below. With the bulk enhancement measured in the experiment $\epsilon_{\mathrm{on} / \mathrm{off}}^{\text {bulk }}$, the putative surface enhancement $\epsilon_{\mathrm{on} / \text { off }}^{\mathrm{S}}$ and the paramagnetic signal loss at the crystal surface $\epsilon_{\theta}^{\mathrm{S}}$, and also using the relative volume of the hyperpolarized surface $V_{\mathrm{s}}$ to the rest $V_{\text {core }}\left(V_{\mathrm{s}}+V_{\text {core }}=1\right)$,

$$
V_{\text {core }}+V_{s} \epsilon_{\text {on } / \text { off }}^{\mathrm{s}} \epsilon_{\theta}^{\mathrm{s}}=\epsilon_{\mathrm{on} / \mathrm{off}}^{\text {bulk }}\left(V_{\mathrm{s}} \epsilon_{\theta}^{\mathrm{s}}+V_{\text {core }}\right)
$$

can be solved for the net surface gain $\epsilon_{\mathrm{on} / \mathrm{off}}^{\mathrm{S}} \epsilon_{\theta}^{\mathrm{s}}$. From this and the room temperature ${ }^{1} \mathrm{H}$ polarization at $B_{0}=16.4 \mathrm{~T}$ of $p=0.0056 \%$, the surface polarization $p_{\mathrm{s}}=p \epsilon_{\mathrm{on} / \mathrm{off}}^{\mathrm{s}} \epsilon_{\theta}^{\mathrm{S}} \epsilon_{\mathrm{Curie}}=3.7-3.9 \%$ for the putative surface signal loss of $\epsilon_{\theta}^{\mathrm{s}}=0.4-0.6$ and with $\epsilon_{\mathrm{Curie}}=300 / 40$. If the crystal size is assumed to distribute between $4-6 \mu \mathrm{m}$ the same calculation with $\epsilon_{\theta}^{\mathrm{s}}=0.5$ yielded $p_{\mathrm{s}}=3.0-4.5 \%$. (b) An optical microscope image of MLF microcrystals. The yellow "spacer symbols" indicate $5 \mu \mathrm{m}$. 

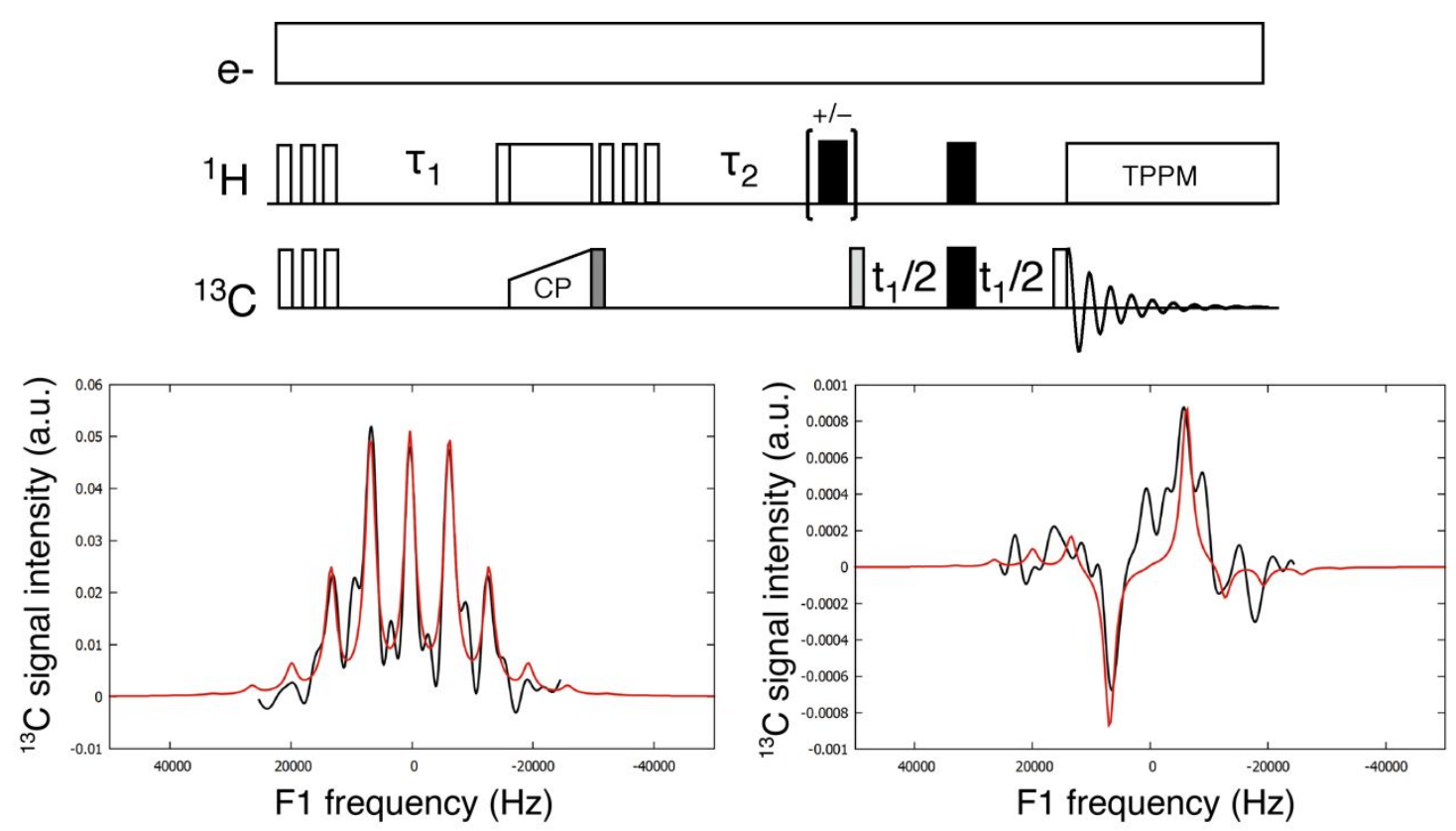

Fig. S7 The surface ${ }^{1} \mathrm{H}$ polarization was quantified using the method we recently developed. ${ }^{[12]}$ The method determines the local absolute ${ }^{1} \mathrm{H}$ polarization through the detection of the NMR signal from the hetero-nuclear spin-correlated component $\left(2 I_{z} S_{Z}\right.$, anti-phase term) of the hyperpolarized magnetization at the crystal surface, separately from that due to the ordinary Zeeman term $\left(S_{Z}\right.$, inphase term). Here, $I$ and $S$ spins correspond to ${ }^{1} \mathrm{H}$ and ${ }^{13} \mathrm{C}$ spins, respectively. In this work, we have modified the original sequence to two-dimensional version as shown in the upper panel to resolve in the indirect dimension the characteristic dipolar-split in-phase (bottom left) and anti-phase (bottom right) powder patterns convoluted with spinning sidebands, each corresponding to the Zeeman- and spin-correlated terms using the isotropic chemical shifts of MLF in the directly-acquired dimension. In the spectra, theoretical fits are overlaid with red lines. 


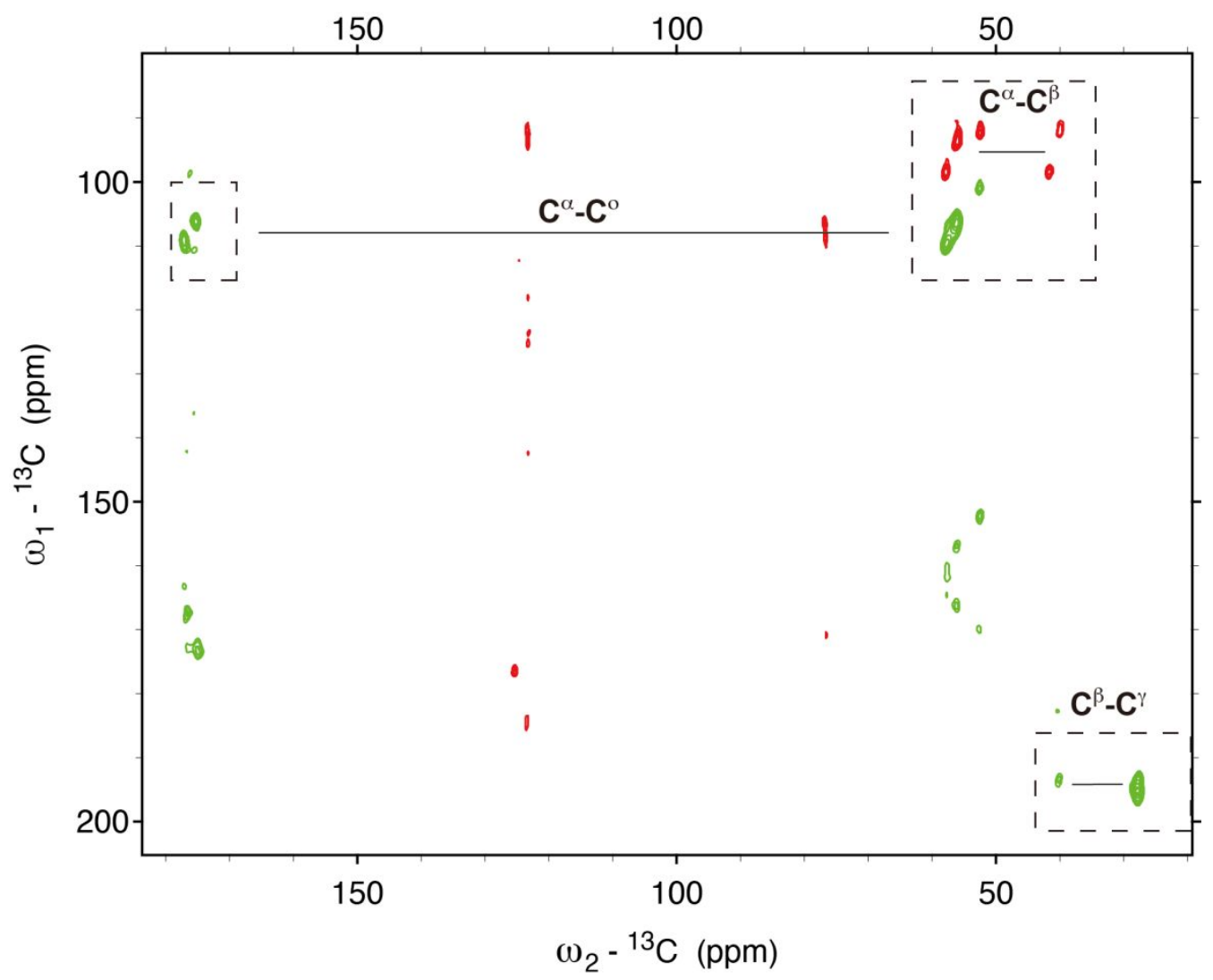

Fig. S8 Full spectral view of the surface-only 2D DQ-SQ spectrum of crystalline MLF powder sample. The thickness of the selected surface will be a function of $T_{1 \mathrm{H}}$ and spin diffusion rate at the surface; in our estimation it was $\sim 130 \mathrm{~nm}$ from the surface. Typical signal-to-noise $(\mathrm{S} / \mathrm{N})$ ratio found in the spectrum was 30-40 for the average surface ${ }^{1} \mathrm{H}$ polarization of $>3 \%$, recorded with 16 scans per $t_{1}$ point for the total experimental time of $\sim 27 \mathrm{hr}$. Most of the expected one-bond DQ-SQ correlations were found except for the $\mathrm{C}^{\beta}-\mathrm{C}^{\gamma}$ (aromatic) peaks of Phe and $\mathrm{C}^{\gamma}-\mathrm{C}^{\delta}$ (methyl) peaks of Leu that may have been disappeared due to line broadenings. Due to the narrow indirect spectral width $(22 \mathrm{kHz})$ dictated by the SPC5 sequence at $v_{\mathrm{R}}=8.8 \mathrm{kHz}$, the sign for the $\mathrm{C}^{\alpha}-\mathrm{C}^{o}$ and $\mathrm{C}^{\beta}-\mathrm{C}^{\gamma}$ peaks are inverted due to aliasing; positive and negative peaks are shown with red and green contours, respectively. The pulse sequence shown in Fig. 3 of the main text can be summarized as [Buildup-CP-( $\pi / 2)$ pulse- $t_{1}$ SPC5(rec)-Acq.]. We used $0.45 \mathrm{~ms}$ for the SPC5 DQ-to-SQ reconversion time. Peak intensities obtained for the $\mathrm{C}^{\alpha}-\mathrm{C}^{\beta}$ DQ-SQ peaks using this pulse sequence were $3.6-4.0 \%$ of those obtained with the conventional DQ-SQ experiment: [Buildup-CP-SPC5(exc)- $t_{1}$-SPC5(rec)-Acq.] for the bulk crystal under same DNP condition. In the latter sequence, we used 0.45 ms-SPC5 recoupling sequence for both exciting and re-conversing the DQ coherence. Theoretically, the signal intensity ratio for these two experiments would be $\sim 5.3 \%$ from following considerations: $(i)$ the polarization buildup and $\mathrm{CP}$ efficiency are identical for both, (ii) the DQ-excitation/reconversion efficiency is close to maximum, 
$\sim 0.73$, (iii) the surface $0.13 \mu \mathrm{m}$ of $5 \mu \mathrm{m}$ spherical crystal corresponds to $15 \mathrm{vol} \%$, which has $\sim 100$ fold enhanced polarization, (iv) the size of the spin-correlated term to the Zeeman term is $\sim 0.04$. From these, estimated normalized peak intensity for the conventional DQ-SQ data would be: $0.73 \times 0.73 \mathrm{x}$ $(0.15+0.85 / 100)=0.084$, while that for the surface-only data would be: $0.04 \times 0.73 \times 0.15=0.00438$, which concludes the ratio is $0.00438 / 0.084=0.052(5.2 \%)$. 


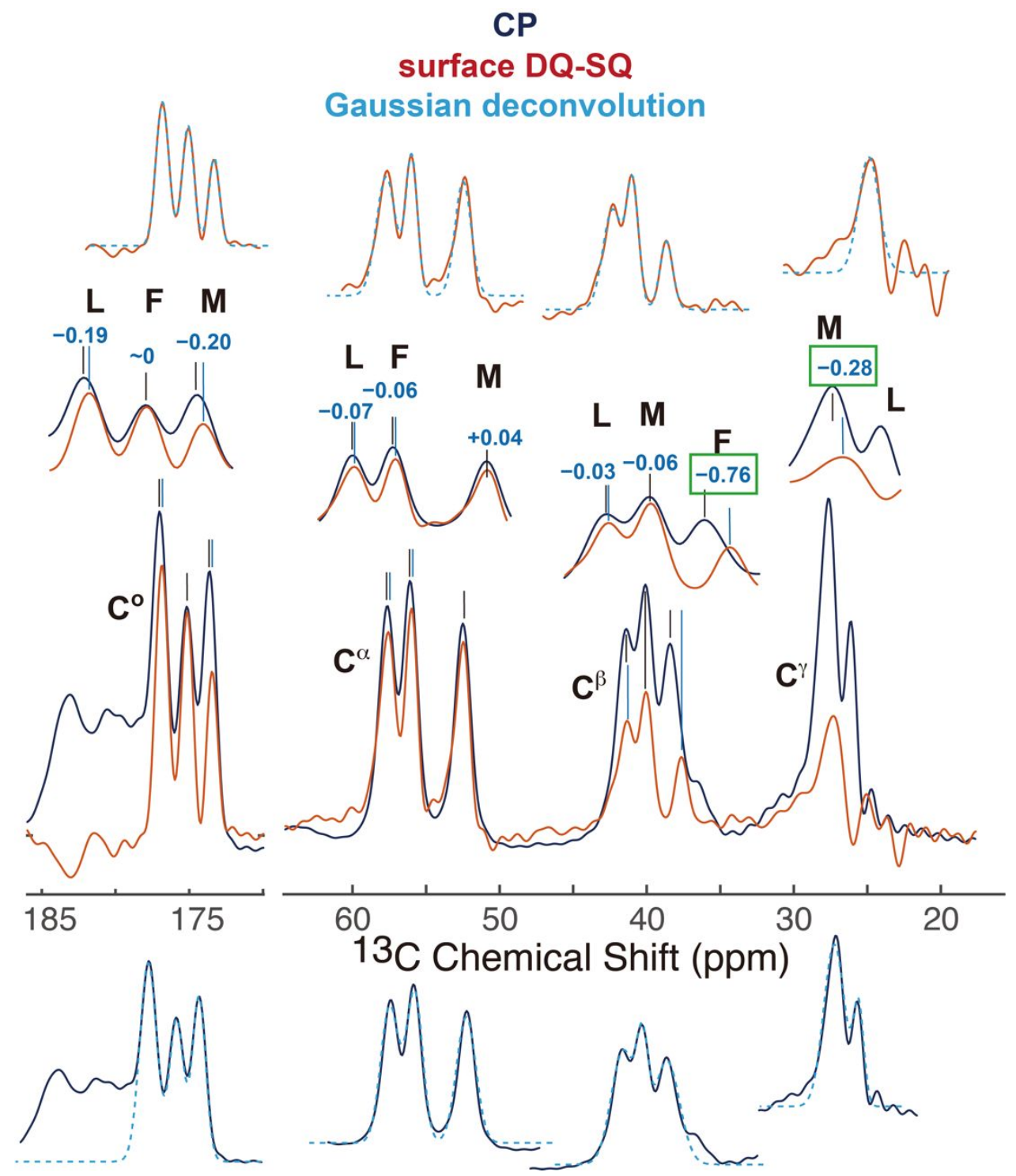

Fig. S9 Fourier transform of the first FID taken from the surface-only 2D DQ-SQ (red) compared with a conventional $\left\{{ }^{1} \mathrm{H}\right\}-{ }^{13} \mathrm{C} \mathrm{CP}$ spectra (dark blue) recorded just before running the 2D DQ-SQ experiment. Blow-ups for the peak-tops are shown above the spectrum to show the slight site-specific peak shifts. These peak shifts are evaluated by deconvoluting the spectrum with a sum of Gaussian functions as shown in light-blue dashed lines and shown in the very top and very bottom of the panel, respectively, for the surface-only data and the conventional data. Peak shifts are listed in Table S2. 
Table S2 Site-specific peak shifts seen between the surface-only DQ-SQ and CP data evaluated by Gaussian deconvolution of the spectra. Relatively large shifts with $\delta>0.3 \mathrm{ppm}$ are shaded.

\begin{tabular}{|c|c|c|c|c|}
\hline Atom & a.a. & $\begin{array}{l}\delta(\mathrm{C})-\delta(\text { surface } \\
\text { DQSQ })\end{array}$ & $\begin{array}{l}\text { Half-maximum } \\
\text { line width }(\mathrm{CP}) \text { in } \\
\text { ppm }\end{array}$ & $\begin{array}{l}\text { Half-maximum } \\
\text { line width (surface } \\
\text { DQSQ) in ppm }\end{array}$ \\
\hline \multirow{3}{*}{$\mathrm{C}^{\mathrm{o}}$} & $\mathrm{M}$ & -0.204 & 1.1 & 1.0 \\
\hline & $\mathrm{L}$ & -0.195 & 1.3 & 1.1 \\
\hline & $\mathrm{F}$ & 0.003 & 1.2 & 1.1 \\
\hline \multirow{3}{*}{$\mathrm{C}^{\alpha}$} & $\mathrm{M}$ & 0.046 & 1.8 & 1.8 \\
\hline & $\mathrm{L}$ & -0.069 & 1.8 & 1.8 \\
\hline & $\mathrm{F}$ & -0.062 & 1.5 & 1.5 \\
\hline \multirow{3}{*}{$\mathrm{C}^{\beta}$} & M & -0.063 & 1.1 & 1.1 \\
\hline & $\mathrm{L}$ & 0.026 & 1.5 & 1.7 \\
\hline & $\mathrm{F}$ & -0.763 & 1.7 & 1.6 \\
\hline $\mathrm{C}^{\gamma}$ & $\mathrm{M}$ & -0.280 & 1.6 & 2.1 \\
\hline
\end{tabular}




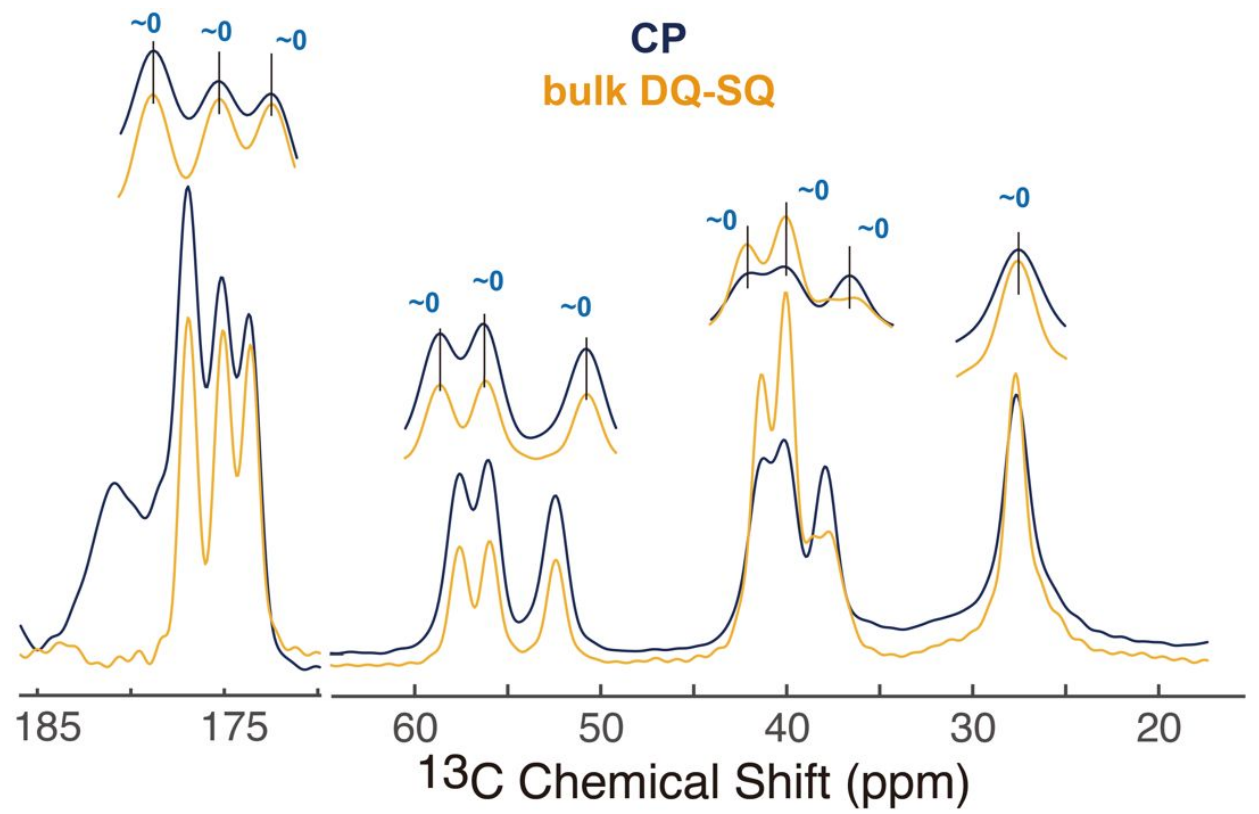

Fig. S10 Fourier transform of the first FID taken from a conventional 2D DQ-SQ dataset (orange) compared with a conventional $\left\{{ }^{1} \mathrm{H}\right\}-{ }^{13} \mathrm{C} \mathrm{CP}$ spectrum (dark blue) taken just before running the $2 \mathrm{D}$ DQ-SQ experiment. Almost no shift was observed between the two data.

[1] M. Rosay, M. Blank, F. Engelke, J. Magn. Reson. 2016, 264, 88-98.

[2] M.-A. Geiger, M. Orwick-Rydmark, K. Märker, W. T. Franks, D. Akhmetzyanov, D. Stöppler, M. Zinke, E. Specker, M. Nazaré, A. Diehl, B.-J. van Rossum, F. Aussenac, T. Prisner, Ü. Akbey, H. Oschkinat, Phys. Chem. Chem. Phys. 2016, 18, 30696-30704.

[3] P. Wenk, M. Kaushik, D. Richter, M. Vogel, B. Suess, B. Corzilius, J. Biomol. NMR 2015, 63, 97-109.

[4] S. Björgvinsdóttir, B. J. Walder, A. C. Pinon, J. R. Yarava, L. Emsley, J. Magn. Reson. 2018, $288,69-75$.

[5] M. Kaplan, A. Cukkemane, G. C. P. Van Zundert, S. Narasimhan, M. Daniëls, D. Mance, G. Waksman, A. M. J. J. Bonvin, R. Fronzes, G. E. Folkers, M. Baldus, Nat. Methods 2015, 12, $649-652$.

[6] Ü. Akbey, W. T. Franks, A. Linden, S. Lange, R. G. Griffin, B. J. Van Rossum, H. Oschkinat, Angew. Chemie - Int. Ed. 2010, 49, 7803-7806.

[7] E. J. Koers, E. A. W. Van Der Cruijsen, M. Rosay, M. Weingarth, A. Prokofyev, C. Sauvée, O. Ouari, J. Van Der Zwan, O. Pongs, P. Tordo, W. E. Maas, M. Baldus, J. Biomol. NMR 2014, 60, 
$157-168$.

[8] G. T. Debelouchina, M. J. Bayro, P. C. A. Van Der Wel, M. A. Caporini, A. B. Barnes, M. Rosay, W. E. Maas, R. G. Griffin, Phys. Chem. Chem. Phys. 2010, 12, 5911-5919.

[9] D. Mance, P. Gast, M. Huber, M. Baldus, K. L. Ivanov, J. Chem. Phys. 2015, 142, 234201.

[10] Q. Z. Ni, E. Markhasin, T. V. Can, B. Corzilius, K. O. Tan, A. B. Barnes, E. Daviso, Y. Su, J. Herzfeld, R. G. Griffin, J. Phys. Chem. B 2017, 121, 4997-5006.

[11] A. C. Pinon, J. Schlagnitweit, P. Berruyer, A. J. Rossini, M. Lelli, E. Socie, M. Tang, T. Pham, A. Lesage, S. Schantz, L. Emsley, J. Phys. Chem. C 2017, 121, 15993-16005.

[12] T. Sugishita, Y. Matsuki, T. Fujiwara, Solid State Nucl. Magn. Reson. 2019, 99, $20-26$. 